\title{
Cantos rituais de tradição na prática do performer': Jerzy Grotowski, Maud Robart e Thomas Richards
}

\author{
Traditional ritual chants in the practice of the \\ performer: Jerzy Grotowski, Maud Robart and Thomas \\ Richards
}

Janaina Trasel Martins ${ }^{2}$

Giuliano Campo $^{3}$ 


\section{Resumo}

Este artigo aborda alguns dos princípios que envolveram o trabalho com os cantos rituais de tradição afro-caribenha praticados na fase da "Arte como Veículo" de Jerzy Grotowski. Serão levantadas percepções sobre essa prática a partir da perspectiva de Grotowski, de Maud Robart e de Thomas Richards. Este estudo propõe reflexões sobre caminhos pedagógicos para a ampliação da consciência criativa do performer sobre a ação vocal, por meio de práticas com cantos de tradição e cantos rituais.

Palavras-chaves: Cantos de tradição; Jerzy Grotowski; Maud Robart

\section{Abstract}

This article discusses some of the principles involved in Jerzy Grotowski's work with African-Caribbean ritual chants at the stage of "Art as Vehicle". Perceptions of this practice will be raised from the perspective of Grotowski, Maud Robart and Thomas Richards. This study proposes reflections on pedagogical paths to expand the performer's creative awareness of the vocal action, through traditional songs and ritual chants.

Keywords: Traditional chants; Jerzy Grotowski; Maud Robart

\footnotetext{
1 Este estudo faz parte da pesquisa de Pós-Doutorado de Janaina Trasel Martins. Bolsista da CAPES - proc. no 10830/13-8. Programa Pós-Doutoral Bolsa CAPES - Brasil, 2014.

2 Universidade Federal de Santa Catarina (UFSC), Profa Dra. Floria-
}

nópolis, SC, Brasil. janaina.martins@ufsc.br

3 Universidade de Ulster, na Irlanda do Norte, Reino Unido. giulianocampo@googlemail.com 
Neste artigo teceremos reflexões sobre a prática vocal de cantos rituais de tradição como um procedimento para a expansão da consciência criativa do perfomer na execução da ação vocal. Para tanto, enfocaremos alguns dos princípios que regeram as práticas com cantos rituais ancestrais afro-haitianos ${ }^{4}$, realizadas pelo encenador polônes Jerzy Grotowski ${ }^{5}$ juntamente com a haitiana Maud Robart ${ }^{6}$, na fase de pesquisa denominada "Arte como Veículo". De acordo com Grotowski (1996), nessa fase eles trabalharam com "ações ligadas aos antigos cantos vibratórios, os cantos que no passado serviram a propósitos rituais e que, portanto, exercem um impacto direto sobre a cabeça, o coração e o corpo dos atuantes". A utilização de cantos ritualísticos como prática para a expansão da consciência é realizada desde tempos remotos, em diversas culturas, com o intuito de evocar a cura, a proteção, a fertilidade da terra, as bençãos na celebração de ritos de passagem, entre outros objetivos específicos. E no trabalho do performer, quais são os objetivos e os princípios que regem as práticas corpóreo-vocais com cantos rituais de tradição? Tendo como foco essa questão, estudaremos as perspectivas de Jerzy Grotowski, Maud Robart e Thomas Richards ${ }^{7}$ sobre seus trabalhos com os cantos rituais de tradição e, a partir deles, articularemos considerações de pesquisadores da área da voz, sobre corpo, memória, tradição e a performatividade da voz.

Grotowski foi um importante encenador do século XX. Sua pesquisa teve diferentes fases, do "Teatro de Produção" a "Arte como Veículo"8. A fase da "Arte como Veículo" começou em Pontedera em 1986, quando Grotowski mudou-se dos Estados Unidos para a Itália e fundou o Workcenter of Jerzy Grotowski; Grotowski faleceu em 1999. Maud Robart trabalhou com Grotowski com os cantos sagrados dell'etnodramma vodu afro-haitiana, do ano de 1977 até 1993. Thomas Richards inicialmente foi um aluno de Grotowski na Universidade Irvine nos Estados Unidos, depois trabalhou como assistente de Grotowski de 1985 até 1999 e hoje é diretor do Programa de Pesquisa em Artes Cênicas no Workcenter of Jerzy Grotowski e Thomas Richards. Juntos, Grotowski, Robart e Richards compartilharam desse trabalho com os cantos vibratórios, nessa fase da "Arte como Veículo". Nos dias de hoje, Thomas Richards continua com o trabalho com as canções de tradições antigas e Maud Robart continua com o trabalho com os cantos rituais da tradição afro-haitiana.

Em todas as fases de trabalho de Grotowski, a sua abordagem esteve centrada no "trabalho do ator sobre si mesmo", de acordo com a tradição Stanislavskiana. No livro "Em busca de um teatro pobre", Grotowski conta que no "Teatro Laboratório" o "trabalho do ator sobre si" estava calcado em um processo de autoconhecimento, em que o ator deveria descobrir as suas limitações pessoais, com objetivo de eliminar os hábitos condicionados, os bloqueios e as resistências que impedem a organicidade na execução da ação físico-vocal (Grotowski, 1987). Na fase da "Arte como Veículo", Grotowski prosseguiu interessado no "trabalho

\footnotetext{
4 "Grande parte do trabalho do Workcenter se realizou e se realiza em torno de cantos de tradição. São cantos, principalmente, mas não só, de origem afro-caribenha (vindos - também principalmente - do vudu haitiano)" (Lima, 2013, p. 223).

5 Diretor teatral Jerzy Grotowski (Rzeszów, 11/08/1933 - Pontedera, 14/01/1999). Considerado por muitas pessoas o principal encenador da segunda parte do século XX.

${ }^{6}$ Maud Robart nasceu em Port-au-Prince, Haiti. Ela vive atualmente
}

no sul da França.

${ }^{7}$ Thomas Richards (B.A. Yale University, M.A. the University of Bologna, Ph.D. University of Paris VIII) é diretor artístico e de pesquisa do "Workcenter of Jerzy Grotowski e Thomas Richards".

${ }^{8}$ A trajetória de Grotowski na arte foi dividida em diferentes fases. São estas: "Teatro de Produções" (1959-1969), "Parateatro" (1970-1978), "Teatro das Fontes" (1979-1982), "Drama Objetivo" (1983-1986) e "Arte como Veículo" (1986-1999) (Campo; Molik, 2012). 
do ator sobre si", porém, o foco não estava mais na "arte como apresentação" e nas suas relações com os espectadores, mas sim o foco do trabalho estava nos atores que realizam a ação performativa. De acordo com a professora Tatiana Motta Lima, "na 'Arte como Veículo' a montagem é feita para atingir a percepção do doer e, portanto, espectadores, renomeados aqui 'testemunhas', podem ou não estar presentes" (Lima, 2014). Nessa fase de pesquisa da "Arte como Veículo", Grotowski decidiu utilizar o termo "performer" no lugar do termo 'ator' para definir a figura do doer, do atuante (Grotowski, 1988). Nesse sentido, compartilha Thomas Richards que "com relação às pessoas diretamente envolvidas na arte como veículo, não penso nelas como 'atores' e sim como 'atuantes' (aqueles que agem), porque seu ponto de referência não é o espectador, mas o itinerário na verticalidade" (Richards, 2012, p.150).

No que diz respeito à verticalidade, a metáfora da escada vertical era utilizada por Grotowski para indicar um caminho para o despertar de outros modos de consciência, de um estado de atenção e de percepção de si ligados à qualidade de presença e à organicidade na ação físico-vocal. A verticalidade "significa passar de um nível supostamente grosseiro - num certo sentido, poderiamos dizer 'nível cotidiano' - para um nível de energia mais sutil, ou até mesmo que busca uma conexão mais elevada" (Ibidem, p. 140). Para Grotowski, "os cantos rituais da tradição antiga dão um suporte para a construção dos degraus dessa escada vertical" (Ibidem, p.141). Maud Robart (2006) também fala sobre a escada vertical como um caminho de expansão da consciência, averigua ela sobre a capacidade dos cantos de despertar a percepção a fim de envolver todas as dimensões do corpo (físico, emocional, mental), para uma transformação dessas energias para uma qualidade mais sutil e perceptiva. Trata-se da expansão da consciência para além de condicionamentos e padrões habituais de pensamento e movimento e de hábitos culturais condicionantes:

A sabedoria combinatória de ligação, através do poder mágico e espiritual da música, a intenção e o gesto, o pensamento e emoção, as palavras, os ritmos, os sons ganha consistência no comportamento, uma comunhão celebrada do artista com todo o seu ser. Tais modos tem como intenção restabelecer a ligação com a energia comum e transversal que abrange todas as formas, aumentando a participação humana acima da esfera pessoal, além da interpretação arbitrária de um ego mundano" (Robart apud Tinti 2006, p. 43) (tradução nossa )9.

No trabalho com cantos e danças ritualísticas afro-haitianas de Maud Robart a busca é pela organicidade, aprofundando as percepções corporais conectadas ao impulso de vida interior de cada indivíduo. Trata-se de uma estratégia pedagógica para provocar relações, aberturas e encontros, consigo mesmo e com os outros (Robart, 2006).

Thomas Richards, que atualmente continua trabalhando com os cantos vibratórios, relata na página oficial do Workcenter of Jerzy Grotowski e Thomas

\footnotetext{
${ }^{9}$ No original: "Una sapienza combinatoria che lega, attraverาso il potere magico e spirituale della musica, l'intenzione e il ge $\urcorner$ sto, il pensiero e l'emozione alla parola, ai ritmi, ai suoni... e che or $g a n i z z a$ la coerenza del comportamento in vista di una comunione coาsmica celebrata dall'artista con tutto il suo essere. Tale modalità, la cui inten-
}

zione è quella di ristabilire il legame con l'energia comune che ingloba e attraversa tutte le forme, innalza anche la partecipazione umana al di sopra della sfera personale, oltre l'interpretazione arbi-traria di un ego mondano" (Robart apud Tinti, p. 43). 
Richards ${ }^{10}$ a visão de que a "arte como veículo" é para ele a investigação sobre a forma, de como as artes do espectáculo podem ser uma ferramenta para a transformação da percepção do artista e de sua presença, um meio de despertar aspectos sutis da experiência através do trabalho com os cantos vibratórios. Informa que a atual equipe de pesquisa sobre a "arte como veículo" está trabalhando com a intenção de entrar em contato com fontes mais íntimas de cada performer para a "transformação de energia", a fim de a arte servir como uma ponte em direção a uma abertura de percepção, não só da performance em si, mas também nas experiências diárias e interações. Nesse sentido a "arte como veículo" não tem como objetivo principal ser destinada a espectadores, ainda que porventura atualmente no Workcenter of Jerzy Grotowski e Thomas Richards eles compartiIhem a experiência com grupos de teatro (Richards, 2012). Sobre a relação entre os cantos de tradição antiga e a obra cênica, conta Tatiana Motta Lima que, no encontro realizado pelo Workcenter of Grotowski and Thomas Richards em dezembro de 1999, em Pontedera, Thomas Richards descreveu que na performance "Action" os cantos de tradição deram suporte ao processo. Tatiana Lima relata que ele deu um exemplo utilizando a imagem de um mapa:

a canção seria como um mapa para o trabalho. Um mapa, como sabemos, dá as referências do percurso, mas não é o próprio percurso. É preciso que o doer, com a boa utilização do mapa, penetre no continente. Richards diz que o canto "pede coisas" ao doer e deve ser seguido com extremo rigor, mas, para segui-lo, me parece claro que o doer deve atualizá-lo, transformá-lo em ato, e é a isso que podemos chamar seu processo ou o processo (Lima, 2014).

Relata Thomas Richards sobre a experiência que teve em uma oficina, na qual Grotowski pediu que cada ator buscasse uma música antiga, que tivesse raízes, conduzindo-os a redescobrir qualquer ligação pessoal a tradição (Richards, 2012, p. 33). A prática envolvia o ato de cantar buscando a ressonância do canto dentro do corpo, de forma a se conectar com algo profundo dentro de si.

Ao alinhavar conexões pessoais aos cantos de tradição, se entrelaçam memória biográfica e memória ancestral. Os cantos ancestrais são ensinamentos transmitidos de século em século, de geração em geração: de voz em voz, de corpo em corpo, de boca ao ouvido, nossos ancestrais até os atuais cantam, recantam e encantam com as canções. Nesses alinhavos entre cantos de tradição e o corpo que canta no instante presente, abrem-se as perguntas:

Quem é a pessoa que canta a canção? É tu? Mas se é uma canção de tua avó? É sempre tu? Se estas tentando explorar a tua avó com os recursos de teu próprio corpo então não é 'tu' e nem 'tua avó' quem canta, é tu explorando a tua avó cantando. Mas talvez vás mais longe. Até algum lugar, até algum tempo difícil de imaginar, onde pela primeira vez se cantou essa canção. [...] Talvez era o momento em que se alimentava o fogo na montanha onde alguém cuidava dos animais. E para reanimar-se com este fogo começou a repetir as primeiras palavras. Entretando, isto não era a canção, era um encantamento, como um mantra. [...] Como

10 Informação acessada no site: http://www.theworkcenter.org/two-teams/focused-reserch-team-in-art-as-vehicle.html. Acesso em: 09 mar. 2014. 
diz a expressão francesa tu es fil de quelqu'un [tu és filho de alguém] [...] Pois os que começaram a cantar as primeiras palavras eram filhos de alguém, de algum lugar. Então se tu encontras isso tu és filho de alguém. Se tu não o encontras, não és filho de alguém, estás cortado, estéril, infecundo. Este exemplo mostra como, a partir de um pequeno elemento - uma canção - se desemboca vários problemas de pertencimento, de aparição da canção, da encantação, de nossos laços humanos, de nossa linhagem no tempo, tudo isso aparece [...] Tu és de algum tempo, de algum lugar. Não se trata de atuar em torno de alguém que não és. Então, em todo trabalho aparece o aspecto vertical, sempre mais até o começo, sempre estar de pé no começo (Grotowski, [1985] 1993, p. 75) (tradução nossa ) ${ }^{11}$.

Dessa forma, o trabalho com os cantos rituais de tradição não pretende uma volta a um passado obsoleto, pois como constata Maud Robart (2006), os cantos são uma herança viva que nos liga diretamente a uma teia interconexa atemporal, nos conectando com nossos antepassados e com as futuras gerações. Em uma trama entre memória histórica e individual, a ancestralidade se atualiza no instante presente do corpo. O corpo presentifica a tradição no momento em que vocaliza os cantos, recriando-os a partir de do engajamento do corpo, de sua presença. Maud Robart compartilha que quando ela trabalha com os cantos rituais de tradição:

Tento lembrar-me de que para transmitir uma canção da Tradição é a realização da essência da música que está em questão...é penetrar na dimensão vibratória do trabalho...que para além destas palavras, eu estou diretamente no momento presente, tentando penetrar no coração da música, para me amarrar à sua pulsação de vida. Sem isso eu não posso ativar o princípio da unidade, a fim de conectar todos os elementos que devem mesclar: meu corpo, minha cabeça e meu coração, eu e outros, a melodia e o ritmo, palavras, respiração, movimentos e sentimentos, a técnica e espontaneidade, tempo e espaço (Robart apud Tinti, 2006, p. 66, tradução nossa) ${ }^{12}$.

A partir dessas considerações, tecemos reflexões de que com os cantos ancestrais ritualísticos acessamos e atravessamos as culturas ancestrais para ancorar a atemporalidade que entrelaça a vocalidade no instante presente. Tecendo reflexões sobre a historicidade da voz, seu uso e as relações entre oralidade, tradição, memória e atualidade, constata o linguista Paul Zumthor ${ }^{13}$ que tradição e memória são permeadas pela movência da própria oralidade. Para ele, a memória tem a função coletiva de atuar como fonte da sabedoria, e tem a função individual de servirse dessa fonte e depositar nela a própria contribuição, sendo que nesse entrelace

\footnotetext{
${ }^{11}$ No original: "¿quién es la persona que canta la canción? ¿Eres tú? Pero si es una canción de tu abuela, ¿es que eres siempre tú? Si estás intentando explorar a tu abuela con los recursos de tu propio cuerpo, entonces no eres "tu" ni "tu abuela" quien canta, eres tú explorando a tu abuela cantando. Pero quizá vas más lejos, hacia algún sitio, hacía algún tiempo difícil de imaginar, donde por primera vez se ha cantado esa canción. [...] Quizá era el momento en que se alimentaba el fuego en la montaña donde alguien cuidaba animales. Y, para reanimarse con ese fuego, alguien comenzó a repetir las primeras palabras. Eso no era todavía la canción, era un encantamiento, como un mantra. [...] Como dice la expresión francesa, tu es fil de quelqu'un. [...]Pues los que empezaron a cantar las primeras palabras eran hijos de alguien, de algún sitio, de algún lugar. Entonces, si tú encuentras eso, tú eres hijo de alguien. Si tú no lo reencuentras, no eres hijo de alguien, estás cortado, estéril, infecundo. Este ejemplo muestra cómo, a partir de un pequeño elemento - una canción - se desemboca sobre varios problemas de pertinencia, de aparición de la canción, de la en-
}

cantación, de nuestros lasos humanos, de nuestro linaje en el tempo, todo esto aparece. [...] Tu eres de algun tempo, de algun lugar. No se trata de actuar el rol de alguien que no eres. Entonces en todo este trabajo aparece el aspecto vertical, siempre más hacia el comienzo, siempre estar de pie en el comienzo" (Grotowski, [1985] 1993, p. 75). 12 No original: "Cerco di ricordarmi che per trasmettere un canto di Tradizione è la realizzazione dell'essenza del canto che è in causa... è penetrare nella dimensione vibratoria del lavoro...Ma, al di la di queste parole, io sono più direttamente nell'istante presente, cercando di penetrare nel cuore del canto, di legarmi alla sua pulsazione vivente. Senza di questo non posso attivare il princi gare tutti gli elementi che devono fonder $า$ si: il mio corpo, la mia testa e il mio cuore, io e gli altri, la melodia e il ritmo, le parole, il respiro, i movimenti e i sentimenti, la tecnica e la spontaneità, il tempo e lo spazio" (Robart apud Tinti, 2006, p.66). 
"o que integra um intérprete que canta na tradição é a ação da voz" (Zumthor, 2001, p. 19). Cada corpo-vocal que canta traz sua marca, sua impressão sobre o canto: "A performance, de qualquer jeito, modifica o conhecimento. Ela não é simplesmente um meio de comunicação: comunicando ela o marca" (Idem, 2007, p. 32). A performance vocal traz em função ativa como ação novas marcas de percepções sensoriais do corpo que está engajado nesse processo. No momento em que vocaliza, o intérprete transforma o signo simbólico, "motiva-o da presença desse corpo do qual emana" (Idem, 2001, p. 20). Assim, a memória é mais do que registros do passado, a memória está presente no aqui e agora, como impulso vivo que se presentifica na presença corpórea. De forma que a ação vocal do canto de tradição se atualiza no instante presente em que o corpo que está vocalizando faz emergir suas próprias marcas biográficas, genéticas, hereditárias. Dessa maneira, os cantos rituais de tradição ampliam a percepção da consciência como uma unidade que transpassa a existência e a temporalidade.

Há um mistério escondido dentro das canções, conforme averiguam Maud Robart e Jerzy Grotowski. Há nos cantos ritualísticos uma mescla alquímica de elementos rítmicos, melódicos e de palavras que atuam como chaves para o acesso aos degraus da consciência. Maud Robart (2006) observa que o mistério contido nos cantos está na combinação da força da intenção, do pensamento, da emoção, das palavras, dos ritmos. Conta Thomas Richards (2012, p.22) que Grotowski orientava os atores a desvendar o mistério escondido nas canções a partir da percepção interna do som ressoando no corpo, da percepção das qualidades vibratórias da canção, não em relação ao tom, mas aos modos de ressonância da canção no corpo, e que assim cada ator buscasse escondido dentro de si mesmo o caminho de se mover em cada canção:

\footnotetext{
Não é apenas uma questão de captar a melodia com sua precisão, ainda que sem isso nada seja possivel. Também é necessário encontrar um tempo-ritmo com todas as flutuações dentro da melodia. Mas acima de tudo, trata-se de algo que é uma sonoridade apropriada: qualidades vibratórias tão palpáveis que de certo modo se tornam o sentido o canto. Em outras palavras, o som se torna o próprio sentido através das qualidades vibratórias; ainda que não se compreendam as palavras, basta receber suas qualidades vibratórias. Quando falo desse 'sentido', falo também dos impulsos do corpo, isso significa que a sonoridade e os impulsos são o sentido, de maneira direta (Richards, 2012, p. 142).
}

Para atingir o núcleo vibratório de cada canção, Grotowski salientava a importância do mantimento da estrutura do canto, melodia e ritmo. De acordo a sua longa pesquisa prática de observação de performers em rituais de diferentes culturas, a precisão é um aspecto fundamental para a qualidade de atenção necessária para a realização de uma performance ritual de elevada qualidade (Grotowski, 1982). Thomas Richards também constata que para descobrir as qualidades vibratórias de um canto ritual de tradição a melodia tem que ser totalmente dominada, pois a precisão é necessária para a manifestação da qualidade vibratória da canção. Ou seja, não deve haver improvisações de forma a alterar a estrutura do canto, ou cantar diversas

\footnotetext{
13 Paul Zumthor, linguista e historiador literário medievalista, traz contribuições sobre a relevância da voz humana nas culturas, desenvolvendo considerações sobre os conceitos de vocalidade,
} 
vezes de maneira diferentes, para que a partir da repetição de uma mesma melodia a qualidade vibratória da canção comece a se manifestar:

O canto de tradição é como uma pessoa. [...] O canto de tradição, com os impulsos ligados a ele, é "uma pessoa". Quando começamos a captar as qualidades vibratórias, isso encontra seu enraizamento nos impulsos e nas ações. Depois de uma hora para outra, esse canto começa a nos cantar. Esse canto antigo me canta; não sei mais se estou descobrindo esse canto ou se eu sou esse canto (Richards, 2012, p. 143).

A fim de chegar à qualidade vibracional das canções, no trabalho de Grotowski e de Maud Robart, o canto era realizado com precisão na estrutura musical e de forma contínua e repetida. Cantar e cantar e cantar continuamente uma canção promove a abertura a outros estados de percepção. Assinala Maud Robart (2006) que para ela os cantos rituais de tradição têm a intenção de restabelecer a ligação com a energia que atravessa todas as formas, em uma ação humana para além da esfera pessoal da interpretação do ego. Com a repetição contínua do canto convida-se a mente a silenciar os condicionamentos racionais pré-estabelecidos e os julgamentos do ego, e a abrir-se para a percepção dos impulsos de vida que percorrem o corpo durante o ato de cantar, ampliando desta forma a consciência da presença do corpo no instante presente da ação vocal. Thomas Richards observa que "consciência significa a consciência que não está ligada à linguagem (a máquina para o pensamento), mas a Presença" (Richards, 2012, p. 140).

O propósito do uso dos cantos vibratórios no trabalho de Grotowski era os elementos de sua ação na expansão da consciência, os impactos do som sobre o corpo, o coração e a cabeça dos artistas, conforme conta Thomas Richards (Ibidem, p. 137). Nesse sentido, Richards compartilha que, na experiência com os cantos rituais de tradição trazidos por Maud Robart, "as canções tiveram um efeito forte sobre mim" (Ibidem, p. 22), constatando que o trabalho com canções vibratórias antigas é um veículo para a transformação das energias das pessoas que cantam.

De fato, em muitas tradições ancestrais os cantos ritualísticos são evocados para facilitar a transformação de energias e os estados de consciência. O professor de práticas xamânicas Ted Andrews ${ }^{14}$ (1996) relembra que os sábios antigos ensinavam que o ritmo, a melodia e a harmonia tem o poder de provocar mudanças no organismo e que a voz é uma linguagem vibratória capaz de movimentar processos em nossas células, bem como nos levar a estados de consciência ampliados. Averigua também o músico Jonathan Goldman ${ }^{15}$ que:

Com os sons é possível mudar os ritmos de nossas ondas cerebrais, nosso ritmo cardíaco e nossa respiração. Os estudiosos têm atribuído faixas de ondas cerebrais distintas aos diversos estados de consciência. Há quatro categorias básicas de ondas cerebrais, baseadas em ciclos por segundo (hertz ou Hz) medidas atribuídas aos sons. São elas: 1) ondas beta - de 14 a $20 \mathrm{~Hz}$, encontradas em nosso estado de vigília ou, consciente; 2) ondas alfa - de 8 a $13 \mathrm{~Hz}$, ocorrem quando meditamos ou nos entregamos a devaneios; 3 ) ondas teta - de 4 a $7 \mathrm{~Hz}$, ocorrem quando entramos

\footnotetext{
14 Ted Andrews 1952 - 2009, foi um professor de práticas xamânicas de cura.
} 
em meditação ou sono profundos, bem como durante atividades xamânicas; 4) ondas delta - de 0,5 a $3 \mathrm{~Hz}$, ocorrem no estado de sono mais profundo e em estados muito profundos de meditação e cura. Os sons podem ser usados para alterar nossas ondas cerebrais, possibilitando a indução de estados alterados. A alteração da faixa de onda cria mudanças de consciência (Goldman, 1994, p. 22).

A ação da voz, por meio de suas frequências vibratórias sonoras, toca, afeta o corpo, compõe e interage com o ambiente. Cantar canções rituais de tradição como procedimento no trabalho do performer demonstra ser um caminho para aprender com as sabedorias ancestrais sobre a expansão da consciência através do som e sobre o potencial criativo da ação vocal na relação consigo, com algo, com alguém e com espaço. Nesse sentido, cantar canções ritualísticas convida a adentramos em contato com as qualidades vibratórias da voz, com a dimensão sonora que vai além da língua e da linguagem simbólica, e que com sua força criativa evoca a própria presença no mundo.

Nesta jornada de cantar canções rituais de tradição adentra-se na cultura para ir além dela: ao cantar vibra-se na eternidade do agora, em que não há separação dentro e fora, há uma teia que nos liga à nossa ancestralidade em ressonância com a totalidade da unidade. Com os cantos rituais de tradição acessa-se o infinito dentro do finito, o eterno dentro do temporal, o passado e o futuro dentro do presente, o individual dentro do coletivo, as memórias biográficas dentro das memórias ancestrais e com esses alinhavos tece-se a teia interconexa que se estabelece no instante presente da ação vocal.

\section{Referências}

ANDREWS, Ted. Sons Sagrados. São Paulo: Mandarim, 1996.

CAMPO, Giuliano; MOLIK, Zygmund. Trabalho de Voz e Corpo de Zygmunt Molik - o legado de Jerzy Grotowski. SP: É Realizações, 2012.

GOLDMAN, Jonathan. Os Sons que curam. São Paulo: Siciliano, 1994.

GROTOWSKI, Jerzy. Tecniche originarie dell'Attore, Seminário di Jerzy Grotowsky all'Universita' di Roma, 1982 (text edited and released in 1983) trans. Luisa Tinti. Universita' "La Sapienza" di Roma (não publicado).

Em Busca de um Teatro Pobre. Rio de Janeiro: Civilização Bra-

sileira, 1987.

Performer. Revista Teatro e Storia. Italia, v.4, n.1, ano 3, p. 163-

169, abril, 1988.

. Tu eres Hijo de Alguien. Máscara - Cuaderno ibero-americano de reflexión e escenologia. México, n. 11, ano 3, p. 69-75, jan 1993.

\footnotetext{
15 Jonathan Goldman é músico e professor nas áreas de harmônicos

e sons de cura. Site: www.healingsounds.com
} 
Cadernos do Simpósio Internacional Workcenter of Jerzy

Grotowski and Thomas Richards. São Paulo: SESC Anchieta, 1996.

LIMA, Tatiana Motta. Considerações Sobre "The Action". Revista Performatus. Ano 2, n. 8, jan 2014. Disponível em: shttp://performatus.net/the-action/>. Acesso em: 12 mar 2014, 16:00.

Cantem, pode acontecer alguma coisa: em torno dos cantos e do cantar nas investigações do Workcenter of Jerzy Grotowski and Thomas Richards. Revista Estudos da Presença, Porto Alegre, v. 3, n. 1, p. 220-240, jan-abr 2013. Disponível em: shttp://www.seer.ufrgs.br/index.php/presenca>. Acesso em $12 \mathrm{mar}$ 2014, 15:00.

RICHARDS, Thomas. Trabalhar com Grotowski sobre as Ações Físicas. São Paulo: Perspectiva, 2012.

TINTI, Luisa. La Ricerca di Maud Robart - L'orizzonte arcaico e atemporale del canto integrato. Biblioteca Teatrale - Revista Trimestrale di Studi e Ricerca sullo Spetacolo. Italia, n. 77, p. 1-205, jan-mar 2006.

ZUMTHOR, Paul. Performance, Recepção, Leitura. São Paulo: Cosac Naify, 2007. . A Letra e a Voz. São Paulo: Companhia das Letras, 2001. 